\section{Rapid one step urine tests in early pregnancy}

SIR, - We were interested in the paper by Mr J C P Kingdom and colleagues on rapid one step pregnancy tests ${ }^{1}$ and the subsequent correspondence. We agree that these pregnancy tests allow many women to be discharged from hospital with less chance of an ectopic pregnancy and accept that they will not diagnose every ectopic pregnancy.

In this unit we have found greater trouble with the false positive results. Two women have had laparoscopies because they had abdominal pain, a positive result of a pregnancy test, and an empty uterus on ultrasound scanning, but the laparoscopies and histological examination of menstrual endometrium showed no abnormality. At least one woman had a planned procedure cancelled because of a result that subsequently proved to be false positive (positive results of Clearview testing twice but negative results of Abbott and Ramp tests). Three couples' false hopes were dashed after positive results of tests done in the infertility clinic were found to be negative on formal checking.

It seems from several letters that the dilution or, conversely, concentration of urine at the time of sampling is an important factor in accuracy. ${ }^{2}$ The manufacturer of the Clearview test has stated that the number of drops is also important. We wonder whether the presence of chemicals in the urine altering surface tension and thus the size of drops may account for errors in the test.

We would caution that, as well as a negative result not always meaning that the woman is not pregnant, a positive result means only that the woman is highly likely to be pregnant.

To be suitable for medical termination women need to be certain at an early stage that they are pregnant. There will be increased pressure to use these tests more frequently, and with greater use more false positive and false negative results will occur. Clinical judgment will thus still be essential, and further formal studies of the positive and negative accuracy of these tests may be warranted.

M E DALTON

LYNDA PRICE

Department of Gynaecology,

District General Hospital,

Sunderland SR4 7TP

1 Kingdom JCP, Kelly T, MacLean AB, McAllister EJ. Rapid one step urine test for human chorionic gonadotrophin in evaluatstep urine test for human chorionic gonadotrophin in evaluat-
ing suspected complications of early pregnancy. BMF 1991; ing suspected complicatic

2 Correspondence. Rapid one step urine test in early pregnancy. BMF 1991;303:57-8. (6 July.)

\section{Is rheumatoid arthritis an infectious disease?}

SIR, - Alan Silman's recent editorial reviews the evidence for a microbial causation to rheumatoid arthritis.' There is, however, another possible association between infectious disease and rheumatoid arthritis.

In west Africa the prevalence and incidence of rheumatoid arthritis are extremely low compared with those in most other populations. ${ }^{2}$ In addition, the disease has a milder clinical course in west Africa. This has led to the hypothesis that one or more tropical infections in the west African subregion may confer a protective effect against the development of rheumatoid arthritis as well as modifying the disease's course. Parasitic infections in general and malaria in particular have been implicated on the basis of both epidemiological evidence and animal studies as giving rise to this protective effect. ${ }^{3}$ The simplest explanation for this apparent phenomenon is a reduction in the sensitivity of immunological mechanisms responsible for producing a breakdown in self tolerance by the massive antigenic stimulus of multiple and heavy parasitaemia. One alternative explanation is that pathogenetic autoantibodies are removed by parasites incorporating host antigen. Genetic factors may also have a role in the protective mechanisms, and indeed the sickle cell gene has been selected and persists in the west African population as a result of the protective effect it confers against malaria in heterozygotes.

Recent studies carried out in west Africa have indicated an association between the HLA class II haplotype DRBI*-1301 and DQBI*-0501 and less severe malarial disease. ${ }^{\star}$ The increased frequency of this class II haplotype in west Africans compared with other racial groups could be responsible for a concomitant reduction in the frequency of haplotypes related to rheumatoid arthritis, such as HLA DR4, as a result of natural selection by malaria, producing a low prevalence of rheumatoid arthritis in areas where malaria is endemic.

Clearly, further studies are required; it would be of great interest if it could be shown that infections may both cause and protect against rheumatoid arthritis.

Rheumatology Research Unit,

A O ADEBAJO

Addenbrooke's Hospital

Cambridge CB2 $2 \mathrm{QQ}$

1 Silman AJ. Is rheumatoid arthritis an infectious disease? $B M \mathcal{J}$ 1991;303:200-1. (27 July.)

2 Lawrence JS. Rheumatism in populations. London: Heinemann 1977

3 Greenwood BM, Herrick EM, Voller A. Can parasitic infection suppress autoimmune disease? Proceedings of the Royal Societ of Medicine 1970;63:19-20.

Hill AVS, Allsopp CEM, Kwiatkowski D, Anstey NM, Twumas $\mathrm{P}$, Rowe PA, et al. Common west African HLA antigens are associated with protection from severe malaria. Nature 1991;352:595-600.

\section{Alcohol consumption during pregnancy and infants' development}

SIR, - Dr M M Madlom asks whether the absolute values of the means obtained from a population survey are directly applicable to the interpretation of measurements made on an individual, without taking into account the statistical theory that underlies the analysis. ${ }^{1}$ The short answer is no.

Our analysis showed that mean of the menta development index was significantly lower in children whose mothers smoked 10-19 cigarettes a day. Our regression analysis took this further. The association between smoking during pregnancy and social class was so strong that once social class was considered the smoking variable was no longer significantly associated with the mental development index. Smoking may still play an aetiological role, because the habit is related to social class, but there may be other factors of importance that are also related to social class. In the case of menta development, social class may be a proxy for the level of mental stimulation the child receives and this alone might be the causal factor. At this stage of our knowledge the message for clinical practice is an affirmation of the need to educate mothers about the importance of giving up smoking and a reminder of the importance of a stimulating environment for the child. We did not make recommendations arising from the results for smoking and social class as the study was not designed to investigate either of these issues.

Our first paper made no reference to 38 weeks or any other gestational period. ${ }^{2}$ We found that the mean value of the distribution of gestational ages of infants born to women who drank $\geqslant 120 \mathrm{~g} /$ week of absolute alcohol was shifted downwards by two weeks in comparison with the mean gestational age of the children of all other mothers. This implies, on the assumption that the shape of the distribution of gestational age is the same for both groups, that there will be proportionally more preterm babies born to the mothers drinking $\geqslant 120 \mathrm{~g} /$ week, an undesirable outcome both for the group and from a public health point of view. This phenomenon has often been discussed in the medical press in relation to the reduction of birth weight in the offspring of mothers who smoke. The clinical relevance of the findings is given in our recommendations.

C DU V FLOREY

D J TAYLOR

Department of Epidemiology and Public Health

University of Dundee, Dundee DDI 9SY

1 Madlom MM. Alcohol consumption during pregnancy and infants' development. BMf 1991;303:646. (14 September.)

Sulaiman ND, Florey C du V, Taylor DJ, Ogston SA. Alcoho

consumption in Dundee primigravidas and its effects on outcome of pregnancy. BMf 1988;296:1500-3.

\section{Soft tissue injuries to the neck}

SIR, - Minerva quite rightly states of our recent paper on whiplash injuries of the neck' that "one of the main prognostic features of long term trouble following whiplash injury is the presence of degenerative changes of the cervical spine." This has been well recognised for several years. ${ }^{34}$

The important finding of our paper was that the incidence of degenerative change was significantly more common in patients who had previously sustained soft tissue injuries of the neck. We also noted that paraesthesia, thoracolumbar back pain, and multiple symptoms were predictive of continuing and severe symptoms.

M GARGAN G C BANNISTER

Department of Orthopaedic Surgery, Princess Margaret Hospital

Swindon SN1 4JU

Views. BMf 1991;303:258. (27 July.)

2 Watkinson A, Gargan MF, Bannister GC. Prognostic factors in soft tissue injuries of the spine. Injury 1991;33:307.

Hohl $M$. Soft tissue injuries of the neck in automobile accidents. f Bone foint Surg 1974;56A:1675.

Miles KA, Maimaris C, Finlay D, Barnes MR. The incidence and
B. prognostic significance of radiological abnormalities in soft prognostic significance of radiological abnormalities in soft
tissue injuries of the cervical spine. Skeletal Radiol 1988; 17:493-6.

\section{Management training of senior registrars}

SIR, - We were interested to read Dr Richard Smith's article on management in the NHS. ${ }^{1}$ We agree that the time has come to change the confrontational attitude that has existed between doctors and managers. As senior registrars in a variety of specialties we felt that our respective training programmes had major deficiencies with regard to the development of the complex management skills that the changed NHS demands. Though only one step down the career ladder, most senior registrars gain little practical experience of the management and administration aspects of consultant practice. There are some excellent courses available, but places are limited and leave of absence may be difficult to obtain for senior registrars working on busy rotations.

In view of this and encouraged by several interested colleagues we set up a local self generated management training group at St James's University Hospital, Leeds. ${ }^{2}$ We organised monthly meetings on topics such as resource management, medical audit, personnel management, the new system of contracts, and the transition from senior registrar to consultant status. We utilised the expertise available within the hospital from management and from consultants. A review after the initial year showed that all the senior registrars who took part found this training helpful. Contributors from hospital management observed that contact with doctors nearer the "shop floor level" than consultants are added new 